\title{
A melting pot world of species: reply to Speziale et al.
}

\author{
Jacques Tassin ${ }^{1}$ and Christian A. Kull ${ }^{2}$ \\ ${ }^{1}$ Centre de Coopération Internationale en Recherche Agronomique pour le Développement, UPR BSEF, 34398 Montpellier, \\ France \\ ${ }^{2}$ Centre for Geography and Environmental Science, Monash University, Melbourne, Australia
}

This is an author archived version of an article published in 2015 in Conservation Biology 29(2): 593-595. For the definitive final version, please go to the Conservation Biology publisher's website http://onlinelibrary.wiley.com/journal/10.1111/(ISSN)1523-1739 (or directly to the article via http://dx.doi.org/10.1111/cobi.12466

Native plants and animals are a natural heritage threatened by one of the six greatest extinction events in Earth's history. Humans, through habitat transformation, exploitation, and species introductions, are driving this extinction event. To turn this tide, Speziale et al. (2014) suggest reducing human dependence on non-native species by increasing the use, harvest, planting, and raising of native species, thereby increasing their cultural and economic value. The search for new or under-appreciated uses of native species is laudable, especially if it helps protect them and contributes to local cultural diversity. Such efforts are arguably an inherent trait of human curiosity and entrepreneurship and are a central platform of popular movements such as slow foods and native gardening. However, Speziale et al.'s hypothesis - that using native species can protect them - is less simple than they suggest. We refute the idea of nativism that underpins Speziale et al.'s proposal and makes it poorly defensible and considered the unaddressed consequences of the proposal for people and for conservation.

\section{Native culture and nativeness}

While there is a case to be made for increasing the prominence of local biodiversity in local cultural and economic life, the native culture proposal rests on problematic assumptions about the meaning of native. Speziale et al. do not define native culture. Based on the contents and spirit of their essay, we assume it refers to local societies, their cultural traditions, and how they interact with their environment. They also do not detail how valuing native species allows native culture to be "recovered" or how native culture and non-native species are incompatible. In contrast, Pfeiffer and Voeks (2008:281) argue that invasive species "affect cultural groups in myriad, often unpredictable and at times contradictory ways" that can be impoverishing, enriching, or provide continuity or reformulation of traditional ethnobiological practices. In many landscapes, people make use of available plants, irrespective of whether they are native, in their cultural lives and for economic reasons (Kull et al. 2013).

The opening lines of Speziale et al. imply that native culture depends on the use of native species. Although early humans undoubtedly used native species, they have also relied on introduced plants for a much longer period than that evoked by Speziale's "eras of colonization." When people migrated out of Africa some 60,000 years ago, their movements likely led to seed dispersal. Domestication then contributed to rapid dispersion of animals and plants. Long before the European eras of colonization, people moved plants to complement local resources, including breadfruit (Artocarpus altilis) and taro (Colocasia esculenta) in the Pacific, fruit trees in the West Indies, and cereals in Eurasia (Stevens et al. 2014).

It is worth repeating the important points that nativeness is spatially and temporally relative, 
that non-nativeness is not a synonym for invasiveness, and that non-native species can contribute to ecological functions as much as natives (Colautti \& MacIsaac 2004; Mascaro et al. 2012; Kull et al. 2013). A preference for native species is a cultural idea, not a natural law (Humair et al., 2014). Biologists first distinguished between native and introduced species in the 1830s (Henslow, 1835), but the value placed on this distinction is a late $20^{\text {th }}$ century phenomenon and is highly contested (Davis et al. 2011). Animals and plants do not make this distinction and interact freely. In emphasising this distinction, Speziale et al. associate threats to biodiversity and ecosystem integrity with non-native species, conflating nonnative with invasive. Similarly, the link between non-natives and highly consumptive societies is not as categorical and causal as Speziale et al. insist - highly capitalized industries form around natives as easily as around non-natives (sometimes they are the same, for example, Atlantic salmon (Salmo salar) aquaculture in the species' native Norway and in their introduced range in Chile or Tasmania).

\section{Pragmatic issues}

There is much to be said for using or cultivating local species. Speziale et al. propose that this will increase their economic and cultural value and thus help conserve them. In contrast, proposals to harvest invasive species in order to control them struggle with the very same consequences: that the increased economic and cultural value arising from their utilization will undermine efforts at control. Yet at a pragmatic level there are a number of downsides to the approach that bear consideration alongside Speziale et al.'s relatively categorical and positive view.

First, from economic and food security points of view, native species tend to have lower productivity. In forestry, for example, trees often grow better in places far from the parasites and pathogens of their native terrain (Zobel et al. 1987). Hence, Acacia mearnsii is much more productive in South Africa and Brazil than in its native New South Wales, Pinus radiata is more productive in New Zealand and Australia than in its native coastal California (Lavery \& Mead 1998).

Second, as a consequence of their lower productivity, the sustainable use of native species compares unfavorably with the greater economic utility, efficiency, and productivity of the world's major crops and livestock, often nonnatives. The main food resources in Africa, for example, were all introduced from other continents: cassava (Manihot esculenta), maize (Zea mays), and bananas (Musa spp.). Different regions have different endowments of species that can be domesticated (Diamond 1998). If societies around the world abandoned what are now traditional (even if non-native) crops, the costs and inefficiencies would be massive, given the long-term investments in breeding and agronomy that have gone into them. The only way to return to surviving on native species would be to greatly reduce human populations.

Third, the increased use of native species, given the current economic system, is not without danger. Commercialization would likely focus on just a few select species, exert intense pressure for gene selection and domestication; and encourage larger plantations or breeding operations that create economies of scale. Speziale et al. suggest that no genetic manipulation be undertaken and that production be limited to agroforestry and low intensity harvesting. For the counterfactual one just has to look at forestry with native trees. This tends to take place in large plantations with intensely bred and selected species, such as Eucalyptus globulus and E. nidens in Australia and Pseudotsuga menziesii in America (El-Kassaby $\&$ Ritland 1996; Jones et al. 2006). Such use of native species in forestry cannot be considered a panacea - the environmental impact of native or exotic species is expected to be similar in plantation monoculture (Zobel et al. 1987). The same goes for animal husbandry: Thorbjarnarson (1999) found that an ex situ approach to crocodile conservation through husbandry and commercialization favored only the most common species and that its sustainability was threatened by market vagaries. 
Finally, the exploitation and husbandry of native species has potentially problematic implications for conservation. The recommendation that reserves and national parks be used as sources of native food and goods could threaten native species in the very places that humans have set aside to protect them. In addition, conservationoriented treaties such as CITES may limit the exploitation of endangered native fauna. For instance, the husbandry of green sea turtles (Chelonia mydas) on Reunion Island was shut down in 1981 due to the listing of this species in CITES Annex 1.

\section{Alternative melting pot views}

Given these concerns, a more defensible proposal could have acknowledged the ecological and cultural relativity of the concept of nativeness. It would then have built an argument around how and why the uniqueness and special values of local biodiversity to human communities in different parts of the world should, and could, gain more prominence in the culture and economic life of those communities in tandem with the non-native components of those landscapes. A strict dualism separating native and non-native species is conceptually problematic and difficult or unproductive to implement in practice. Alternatives can be found through mixed postures. Our world is not one where native and non-native landscapes stand in stark separation; rather, it is an increasingly mixed world. Such a conciliatory posture draws on Soulé's (1990) "mixecology" and more recent approaches such as "melting pot systems" and "novel ecosystems" (Hobbs et al. 2013; Kull et al. 2013). In these approaches, landscapes may be mixed, but they are not necessarily homogenous, ecologically dangerous, or culturally valueless. Time has shown that nonnative species can be rapidly integrated in sustainable rural agriculture or agroforestry and integrated into cultural traditions (Kull et al. 2013). For instance, non-native species with medicinal uses are rapidly incorporated into ethnobotanical practices (Pfeiffer \& Voeks 2008). Even conservation and ecotourism sometimes rely on anthropogenic landscapes with non-native plants (e.g. abandoned village sites with Psidium cattleianum in Ranomafana National Park, Madagascar). Local livelihoods and cultures can be in tune with surrounding biodiversity without being dogmatic about nativism.

We agree with Speziale et al. that the consequences of reliance on exotic species must be carefully considered. But conversely, it should be recognized that many countries cannot afford long native species domestication programs, that some resources are not substitutable, that useful species are not evenly distributed around the planet, and that the use of already domesticated and assessed non-native species is often the most effective and rational means to supply human needs. Furthermore, even if strong ecological arguments existed to promote the wide scale domestication and planting of native species, the question remains how? The research, education, monitoring, and funding needed would be pitted against the much stronger forces of commodity markets, politics, and human nature. If Speziale et al.'s argument were stretched to its logical conclusion, only Peruvians would cultivate potatoes, only Iraqis would cultivate wheat, and only New Guineans would cultivate bananas. The world would starve, and there would be no guarantee that native species would be any better off.

\section{Literature Cited}

Colautti, R. I., and H. J. MacIsaac. 2004. A neutral terminology to define 'invasive' species. Diversity and Distributions 10:135-141.

Davis, M. A. et al. 2011. Don't judge species on their origins. Nature 474:153-154.

Diamond, J. 1998. Guns, germs, and steel. Norton, New York.

El-Kassaby, Y. A., and K. Ritland 1996. Impact of selection and breeding on the genetic diversity in Douglas-fir. Biodiversity \& Conservation, 5:795-813.

Humair, F, Siegrist M., Edwards P. J., and C. Kueffer. 2014. Understanding misunderstandings in invasion science: why experts don't agree on common concepts and risk assessments. Neobiota, 20:1-30.

Henslow, J. S. 1835. Observations concerning the 
indigenousness and distinctness of certain species of plants included in the British floras. The Magazine of Natural History 8:84-88.

Hobbs, R. J., E. S. Higgs, and C. Hall, 2013. Novel Ecosystems. Wiley, New York.

Jones, T. H., D. A. Steane, R. C. Jones, D. Pilbeam, R. E. Vaillancourt, and B. M. Potts. 2006. Effects of domestication on genetic diversity in Eucalyptus globulus. Forest Ecology and Management 234:78-84.

Kull, C. A., S. Carrière, S. Moreau, H. Rakoto Ramiamantsoa, C. Blanc-Palmard, and J. Tassin 2013. Melting pots of biodiversity: tropical smallholder farm landscapes as guarantors of sustainability. Environment 55:6-16.

Lavery, P. B., and D. J. Mead. 1998. Pinus radiata: a narrow endemic from North America takes on the world. Pages 432449 in D. M. Richardson, editor. Ecology and Biogeography of Pinus. Cambridge University Press, Cambridge.

Mascaro, J., R. F. Hughes, and S. A. Schnitzer. 2012. Novel forests maintain ecosystem processes after the decline of native tree species. Ecological Monographs 82:221228.

Pfeiffer, J. M., and R. A. Voeks. 2008. Biological invasions and biocultural diversity: linking ecological and cultural systems. Environmental Conservation 35:281-293.

Soulé, M. 1990. The onslaught of alien species, and other challenges in the coming decades. Conservation Biology 4:233-239.

Speziale K. L., S. A.Lambertucci, C. P. Souto, and F. Hiraldo. 2014. Recovering native culture in a world of non-native species. Conservation Biology DOI:

10.1111/cobi.12251.

Stevens, C. J., S. Nixon, M. A. Murray, and D. Q. Fuller, editors. 2014. Archaeology of African Plant Use. Left Coast Press, Walnut Creek.

Tassin, J. 2014. La grande invasion : qui a peur des espèces invasives? Odile Jacob, Paris.

Williamson M. 1996. Biological Invasions. Springer, New York.
Zobel, B. J., G. van Wyk, and P. Stahl. 1987. Growing exotic species. Wiley, New York. 